\title{
New Trends in Hydroprocessing Spent Catalysts Utilization
}

\author{
Hoda S. Ahmed and Mohammed F. Menoufy \\ Egyptian Petroleum Research Institute \\ Egypt
}

\section{Introduction}

The distillate of crude oil is an essential step in the petroleum refining practice. The yield and properties produced distillates depend on the properties of crude oil, distillation conditions and the type of distillation column. Primary distillates are subjected to an additional treatment to meet the environmental requirements and the performance of produced fuels. The schematics of a typical refinery operation processing a conventional crude shown in Fig. 1 lists four catalytic processes, i.e. reforming, hydrocracking, hydrotreating, catalytic cracking and alkylation. The residue from atmospheric distillation may be subjected to additional distillation under a vacuum to obtain valuable lubricant fractions which also require catalytic hydrotreatment. None- conventional refineries can process heavy oils and distillation residues. In this case, the catalytic hydro cracking of the heavy feed is usually the first step, followed by hydrotreating of the synthetic distillates. For the purpose of this review, the hydroprocessing will refer to both hydrocracking and hydrotreating. Light hydrocarbon which is byproducts of several refineries can converted to high octane fractions by catalytic alkylation and polymerization.

\subsection{Refining catalysts ${ }^{(2)}$}

Several operations employing a catalyst may be part of the petroleum refinery. The management of catalyst inventory represents an important part of the overall refinery cost. As shown in Fig. 2, the development of refining is closely connected with the growth of the use catalysts. In the past, refining catalysts accounted for more than half of the total worldwide catalyst consumption. Today because of the importance of environmental catalysis, refining catalysts account for about one third of the total catalyst consumption. Future advances in development of more active and stable catalysts may further decrease the overall consumption of refinery catalyst.

The solid catalysts are usually of none noble metal catalysts and noble types. None-noble metal catalysts include base metals and zeolites. Nobel metal catalyst includes a variety of precious metals from the platinum group. In many cases, catalytically active metals are combined with a solid support such as alumina, silica-alumina, zeolites, carbon, etc. 


\subsection{Catalyst demand worldwide ${ }^{(3-5)}$}

The oil refining industry operation is analyzed in order to estimate the future catalyst market trends. The refining catalyst market corresponding to the main catalytic processes is estimated taking into account the following information: (i) the average refining capacity increases for the main catalytic processes since 1999, (ii) the additional refining capacity due to future plans of construction and expansion of refineries and process units that will be added by 2005, and (iii) the past refining catalyst market behavior. From this information, it has determined for the main catalytic processes a global average factor, expressed as processed oil barrels per dollar of catalyst. According to the catalyst Group Research Co, the global refining catalyst market has grown from $\$ 2.32$ billion in 2001 to about $\$ 2.65$ billion in 2005 (3.6\% annual growth). Hydrotreating, fluid catalytic cracking, hydrocracking and isomerization represent about $74 \%$ of the total catalyst market and will grow by about $\$ 34$, $\$ 32, \$ 11$ and \$2.5 million per year, respectively. However, naphtha reforming catalyst market will not grow during 2001-2005. Higher catalyst spending growth is expected for the North America region (\$27.5 million per year)

Worldwide refiners need to produce cleaner fuels and operate to meet environmental regulations. Therefore, refineries should convert more heavy feedstock's to satisfy regional fuel market needs, and minimize their profit margins which guides the developments in the refining catalyst market. Refiners require more processing capacity and higher efficiency to satisfy regional fuel market needs., therefore, more catalyst consumption is needed and in the same be more resistant to deactivate under sever operating conditions. Table 1 gives the refining catalyst market in tons and dollars by application for 1999 and 2005.

\begin{tabular}{|l|c|c|c|c|c|c|}
\hline Process & \multicolumn{3}{|c|}{1999} & \multicolumn{3}{c|}{$\mathbf{2 0 0 5}$} \\
\hline & $\mathbf{1 0}^{\mathbf{3}}$ tons & $\mathbf{0}$ & G\$ & $\mathbf{1 0}^{3}$ tons & \% & G\$ \\
\hline Cracking & 495 & 77 & 0.7 & 560 & 73.6 & 0.83 \\
Hydrotreatments & 100 & 15.5 & 0.72 & 135 & 17.7 & 0.96 \\
Hydrocracking & 7 & 1.1 & 0.10 & 9 & 1.2 & 0.12 \\
Reforming & 6 & 0.9 & 0.12 & 7 & 0.9 & 0.15 \\
Others* & $\sim 35$ & 5.5 & 0.56 & $\sim 50^{* *}$ & 6.6 & 0.64 \\
Total solids & $\sim 640-650$ & 100 & 2.2 & $\sim 760$ & 100 & 2.7 \\
Alkylation & $3100^{* *}$ & - & 0.85 & $3700^{*}$ & - & 1 \\
\hline
\end{tabular}

*Catalyst for $\mathrm{H} 2$ production, polymerization ,isomerization etherification ,claus ,lubes, etc **Approximate values.

Table 1. World catalyst market in refining.

The refining catalyst market is the most competitive segment of the global catalyst. This market was increased at about 1.9\% / year during 2001-2007. Two different catalyst market estimates 1 and 2 (Table 2) were developed according to the increasing refinery capacities or to the added capacities due to revamps, or expansion plans. Table 2 shows the future catalyst markets according to these estimates. The data indicate that the current catalytic processes, hydrotreating, FCC, naphtha reforming, hydrocracking and isomerization, represent about $77 \%$ of the total refining catalyst market. The future catalyst market will increase through 2007- 2008 to about \$ 2.58 billion (2.8\%/ year). Most growth was occurred 
in North America, Asia Pacific, and the Middle East. If the catalytic prices remain unchanged, then the future worldwide catalytic processes consumption will be about:

Hydrotreating

FCC

Naphtha reforming

Hydrocracking
117,778 tons

357,612 tons

7,273 tons

5,538 tons

\begin{tabular}{|l|c|c|}
\hline & $\begin{array}{c}\text { Estimate.1 2007 catalyst } \\
\text { market Million \$ }\end{array}$ & $\begin{array}{c}\text { Estimate..2 2007 catalyst } \\
\text { market Million \$ }\end{array}$ \\
\hline Hydrotreating & 897 & 954 \\
\hline FCC & 716 & 751 \\
\hline Naphtha reforming & 139 & 144 \\
\hline Hydrocracking & 132 & 144 \\
\hline Isomerization & 58 & 64 \\
\hline Total & 1,941 & 2,057 \\
\hline
\end{tabular}

Table 2. Future catalyst market.

\subsection{Catalysts deactivation ${ }^{(6-10)}$}

In every catalytic operation, the activity of the catalyst gradually decreases. This decrease can be offset by changing some operational parameters. However, at a certain point, catalyst replacement is inevitable. The spent catalysts can be regenerated and returned to the operation. The regeneration of spent hydroprocessing, fluid catalytic cracking (FCC) and reforming catalysts has been performed commercially for several decades. These regeneration processes have been extensively reviewed by Furimsky and Massoth .Hughes and Fug.

Large quantities of catalysts are used in the refining industry for operation and upgrading of various petroleum streams and residues. The catalysts deactivate with time and the spent catalysts are usually discarded as solid wastes. The quantity of spent catalysts discharged from different processing units depends largely on the amount of fresh catalysts used, their life and the deposits formed on them during use in the reactors. In most refineries, a major portion of the spent catalyst wastes come from the hydroprocessing units. This is because the catalysts used in these processes deactivate rapidly by coke and metal ( $\mathrm{V}$ and $\mathrm{Ni}$ ) deposits, and have a short life due to fouling of the active catalytic centers by these deposits. Furthermore, technology for regeneration and reactivation of the catalysts deactivated by metal fouling is not available to the refiners.

The volume of spent hydroprocessing catalysts discarded as solid wastes has increased significantly in recent years due to the following reasons:

- $\quad$ rapid growth in the distillates hydro processing capacity to meet the increasing demand for ultra low-sulfur transportation fuels.,

- a steady increase in the processing of heavier feed stocks containing higher sulfur, nitrogen and metal (V\&Ni) contents, and 
- rapid deactivation and unavailability of a reactivation process for reside hydroprocessing catalysts.

In Kuwait's refineries, over 250000 barrels of heavy residues higher in sulfur, and metals are upgraded and converted to high quality products by catalytic hydroprocessing, bringing substantial economic returns to the country. These operations generate a substantial amount of deactivated spent catalysts as solid waste every year. Currently, about 6000 tons of spent catalysts are discarded as solid wastes from Kuwait's refineries annually. This will increase further and exceed 10000 tons/y when a fourth refinery is built to process heavy crudes and residues.

In Egyptian refiners, the solution is different, due to schematic refining processing such as, hydrotrating, isomerization and reforming process. The only full refining system was found is Medor refining which contains, beside the hydrotreting units, a conversion unit (hydrocracker) using less contaminants heavy residues. Therefore, the current discarded spent catalysts have fewer amounts, i.e. nearly 400-700 tons / y, but can be increased due to the future addition of new refining instillations.

\subsection{Environmental considerations ${ }^{(10-12)}$}

Environmental laws concerning spent catalyst disposal have becomes increasingly more severe in recent years. Spent hydroprocessing catalysts have been classified as hazardous wastes by the Environmental Protection Agency (EPA) in the USA. The most important hazardous characteristic of spent hydroprocessing catalysts is their toxic nature. Metals such as $\mathrm{V}, \mathrm{Ni}, \mathrm{Mo}$ and Co present in the catalyst can leached by water after disposal and pollute the environment. Besides the formation of leachates, the spent hydroprocessing catalysts, when in contact with water, can liberate toxic gases. The formation of dangerous HCN gas from the coke deposited on hydroprocessing catalysts that contains substantial amount of nitrogen has been reported. The solid spent refinery catalysts will refer to as non-regenrable catalysts and the hazardous nature of the spent catalysts is attracting the attention of environmental authorities in many countries and the refiners are experiencing pressures from environmental authorities for safe handling of spent catalysts.

In the USA, the disposal and treatment of spent refinery catalysts is governed by the Resource Conservation and Recovery Act (RCRA), which holds not only the approved dumb-site owner liable. but also the owner of the buried waste. This environmental responsibility continues for the life of the dumb-site. The current RCRA regulations require landfill to be built with double liners as well as with leachate collection and groundwater monitoring facilities. Thus, the landfill option is becoming expensive today. In Addition, it carries with it a continuing environmental liability. Treatment prior to land filling may be necessary in some cases, further increasing the cost.

\subsubsection{Hazardous characteristics of spent hydroprocessing catalyst ${ }^{\text {(13-16) }}$}

The hazardous nature of hydroprocessinig catalysts depends on operating conditions. However, the procedure applied during the catalyst withdrawal from the reactor at the end of the operation can be even more important. If a proper procedure can be applied, the hazardous cane be significantly minimized. For example, if a hydroprocessing catalyst 
cane be treated with either an inert gas or steam, and/ or $\mathrm{CO}_{2}$ in the absence of $\mathrm{H}_{2}$ and feed, and at a near operating temperature, the amount of the carried over liquids can be substantially decreased. The amount of entrapped volatile gases, which may include even $\mathrm{H}_{2}$,can be decreased as well. Without a proper pretreatment prior to the catalyst withdrawal the concentration of flammable vapors above the solid material may reach dangerous levels. In some cases, e.g. when special precautions were not taken during the catalyst withdrawal, it may be appropriate classify the hazardous characteristics of spent hydroprocessing catalysts as that of the corrosive and flammable liquids. One information source indicates catalyst unloading under vacuum. It is stated that this method removes the catalyst without disturbing the operation, however, the type of catalyst and / or operation is not specified.

It a appears that there is no safe catalyst withdrawal procedure which could be generally accepted by all refiners.

Refiners usually apply their own procedure. The need for a commonly accepted and/or approved procedure may develop in the future. In this regards several patents describing the catalyst unloading techniques should be noted. These techniques can significantly reduce or even eliminate the self-heating character of spent catalyst. Otherwise, if spontaneous combustion begins, the inorganic sulphides and organic sulphur which are part of the spent catalysts may also contribute to the uncontrolled burn off. In such case, they will produce large quantities of $\mathrm{SO}_{2}$. However, sulfides alone require temperatures exceeding $200^{\circ} \mathrm{C}$ for spontaneous combustion to occur. Part of nitrogen in coke will be converted to NOx during the spent catalysts burn off. Though the evolution of HCN and $\mathrm{NH}_{3}$ is also possible. Fig. $3 \& 4$ show the formation of $\mathrm{HCN}$ and $\mathrm{NH}_{3}$ during oxidation of spent CoMo, Ni Mo catalysts in $4 \% \mathrm{O}_{2}$.

\section{New trends in utalization ${ }^{(17-19)}$}

Several alternative methods such as disposal in land fills, reclamation of metals, regeneration/ rejuvenation and reuse, and utilization as raw materials to produce other useful products are available to the refiners to deal with the spent catalyst problem. The choice between these options depends on technical feasibility and economic consideration.

Nowadays, in order to alleviate the shortage of domestic resources and improve the environmental condition, many countries in the world pay much attention to the comprehensive utilization of the secondary resources. In Japan, recycling of the waste catalysts has been done since 1950s; the turnover of waste catalysts was already up to 500 million dollars in 1996.

Thus, the landfill option is becoming expensive today. In addition, it carries with it a continuing environmental liability. The potential future liability of landfills is estimated at about $\$ 200 /$ ton. Treatment prior to land filling may be necessary in some cases increasing the cost. In the face of lower- sulfur regulations and regulations deterring catalysts from entering landfills, refiners have directed spent- catalysts traffic from disposal options to regeneration and reclamation plants. 


\subsection{Recovery of metals ${ }^{(20-29)}$}

In recent years, increasing emphasis has been placed on the development of processes for recycling and recovering of the waste catalyst metals, as much as possible. In literature there are many applied researches for spent metals recovery, particularly for catalyst that contain high concentrations of valuable metals $\left(\mathrm{Mo}, \mathrm{Ni}, \mathrm{V}\right.$ and $\mathrm{Al}_{2} \mathrm{O}_{3}$ ) However, fluctuations in the market prices of the recovered metals and their purity, together with the high costs of shipping significantly influence the economics of the metal reclamation process making it less attractive for spent catalysts that contain low metals concentrations.

As the environmental pressure increases, and as the cost of catalyst storage and disposal continues to rise, the utilization of spent refinery catalysts for metal recovery is becoming a viable pollution. Therefore, the refiners are ready to supply spent hydroprocessing catalysts free of charge in order to reduce their costs for storage and disposal. If the market value of the recovered materials is high enough, then it will offset, the processing cost yielding, a net profit to the reclaimer companies.

\subsection{Reactivation/rejuvenation and reuse}

Many literature review revealed that reactivation of spent catalysts technology did not reach to well developments. Spent catalysts lose their activities, and deactivated by pore blockage and fouling of the active surface with deposition of coke and metal contaminants. Therefore, many efforts were subjected to replace the conventional regeneration procedures in order to reactivate and rejuvenate the spent catalysts. The new procedures are conducted to remove contaminant metals selectively by chemical treatments without significantly affecting the chemical and physical characteristics of the original catalyst.

In some experimental works in EPRI (1), we were succeeded in rejuvenating spent catalyst $\mathrm{Mo} \mathrm{Ni} / \mathrm{Al} 2 \mathrm{O} 3$ after re-refining of waste lube oil. Our data revealed that the treated spent catalyst can be restored to nearly the fresh HDS activity levels by application of oxalic acid leaching technique in addition to $\mathrm{H} 2 \mathrm{O} 2$ as an oxidizing agent. The most effective leaching agent was $4 \%$ oxidized oxalic acid, and the extent of metals recovered was dependent on acid concentrations or the specific reuse of the spent catalyst. The rejuvenation process promotes the formation of a hydroprocessing catalyst due to improvements in surface area and average pore diameter $(87 \%$ and $63 \%$ of fresh catalyst characteristics, respectively) as a result of metals recovery. These improvements caused recovery in the HDS activity of the treated catalyst in the range of $81-96 \%$ compared to the activity of the fresh, $95-98 \%$, within reactor temperatures $3401 \mathrm{C}-380_{1} \mathrm{C}$ figure 1 . Therefore, it is clearly possible to reuse the rejuvenated catalyst, especially in the refining processes, as a top-layer guard-bed or mixed with the same fresh catalyst (2-3).

Other improvements were also obtained in catalyst activities by leaching, especially prior to decoking, either using $2 \%$ or $4 \%$ leaching concentration. The results indicate that removing coke from the leached catalysts increases its cyclohexene conversions as well as its hydrogenation and isomerization activities figure 2. These results suggested that coke deposition has less effect than metals in deactivating hydrotreating catalysts. The treatments 


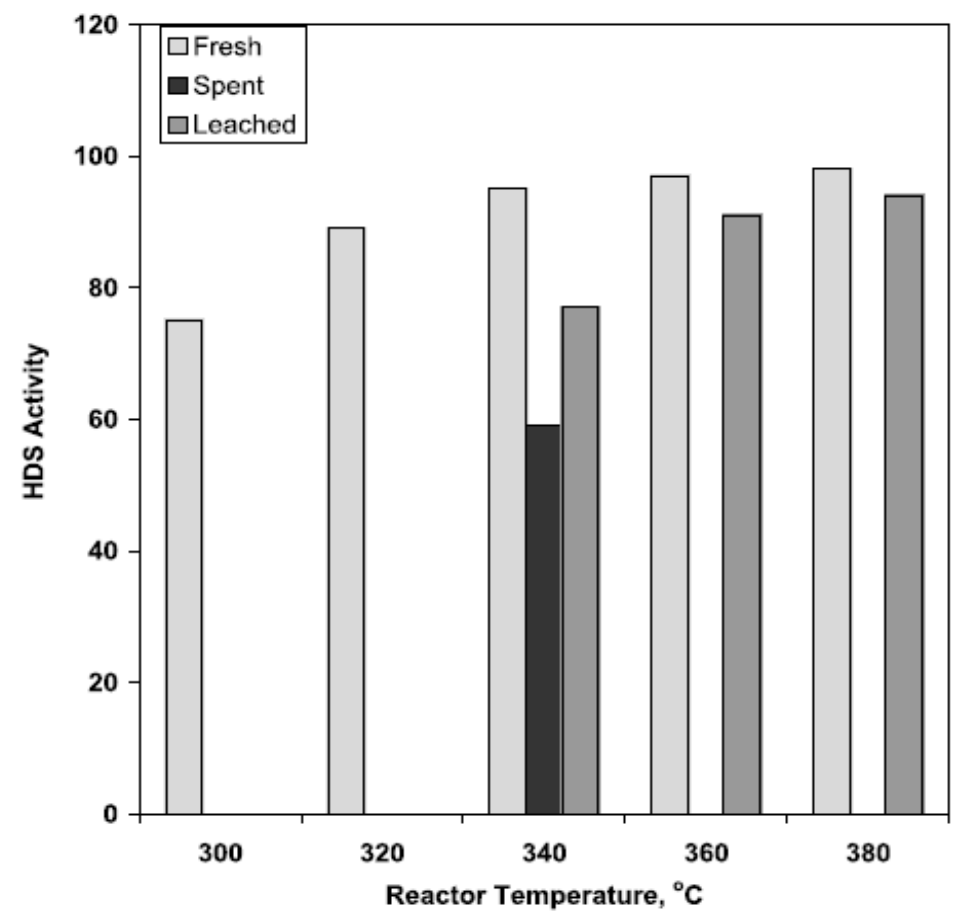

Fig. 1. Relative hydrodesulfurization (HDS) activity of fresh spent and leached catalysts under variable reactor temperature.

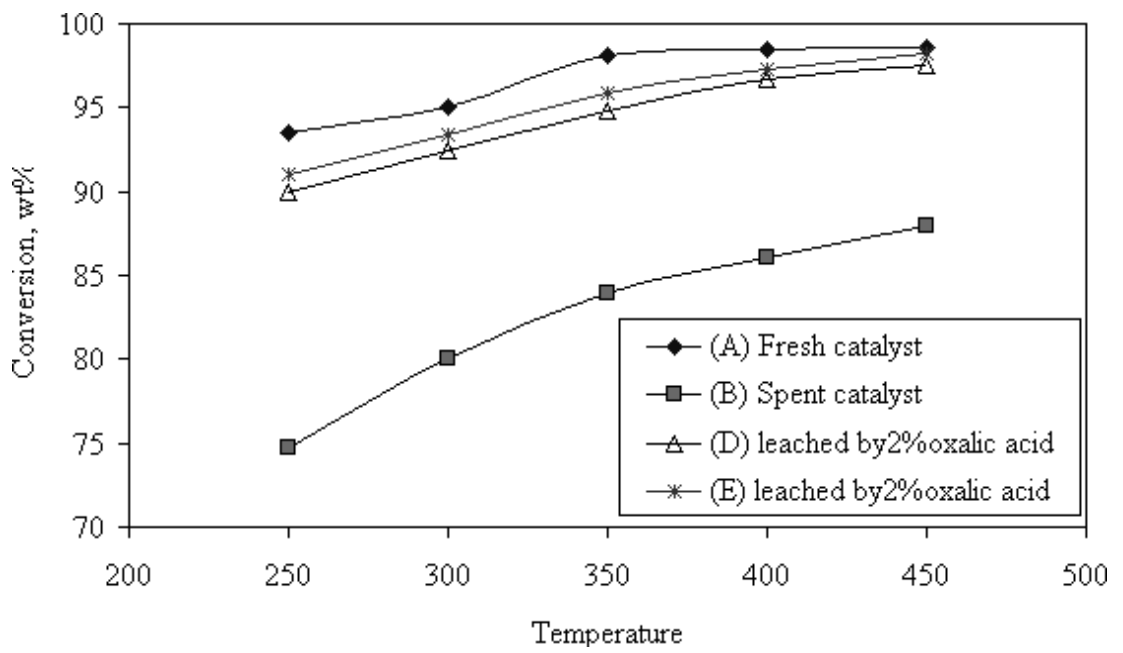

Fig. 2. Effect of reaction temperature on cyclohexene conversion when using catalysts: fresh (A) spent (B) decoked before (D) and after (E) leached by $2 \%$. 
developed in the present work appear to be very promising for reactivation (rejuvenation) of hydrotreating spent catalysts in order to recycle the solid spent catalysts and thereby reducing their environmental problems of disposal. (4).

\subsection{Utilization of spent catalysts as raw materials}

Utilization of spent catalysts as raw materials in the production of other valuable products is an attractive option from environmental and economical points of view. Spent fluid catalytic cracking (FCC) catalysts have been successfully utilized in cement production. In the U.S., cement kilns process about 60,000 tons/year of spent FCC catalysts.

\section{Concluion}

The volume of spent hydroprocessing catalysts in the Arab countries discarded, as solid wastes, has increased significantly due to:

1. Increasing in processing moderate and / or heavier feedstocks.

2. Rapid growth in the distillates hydroprocessing capacity.

3. Increase the environmental regulations for fuel emissions.

4. In Kuwait alone, around 7000-10000 t / y spent catalysts are generated every year more than the other Gulf Countries. In Egypt, the volume of spent catalysts is nearly around 400-700 $\mathrm{t} / \mathrm{y}$, depends on the type and volume of the refined feedstock. Therefore, the choice of the Kuwait refiners was focused now on two processes, one for rejuvenation of spent residue hydro treating catalysts, and the other for producing non-leachable synthetic aggregate materials or loaded as front end- reactors (HDM, guard beds).

Handling and utilization has been the subjected of some investigations in the Kuwait (KISR) and Egypt (EPRI) laboratories. In most of the previous studies in both laboratories, rejuvenation of spent hydroprocessing catalysts for reuse was addressed. Up to $70-80 \%$ of the spent catalyst was reclaimed, in the applied processes of both laboratories, with HDS activity as high as $94-95 \%$ of fresh catalyst. Therefore, from the economic point of view, the rejuvenation and reuse of the catalyst is feasible with an internal rate of return.

In KISR, the researchers have been succeeded in preparing hydride- metallization (HDM) catalysts, by the addition of boehmite.

The resulted catalyst are used in the front-end of reactors used in petroleum residue hydrotreating processes to remove the foulant metals ( $\mathrm{V}$ and $\mathrm{Ni}$ ). The catalyst posses high activity for promoting HDM reactions together with some activity for HDS reactions.

\section{References}

[1] Inui, K .Res.Inst France Petrol (IFP).(49),5,1571 (1994).

[2] Martino, G. Bull. Soc. Chem.Fr.131, 444 (1994).

[3] Silvy,R.I. Refining catalyst business shows signs of strong recovery in 2004-07. Oil \& Gas J. 102 (16), 58-65, April 26 (2004). 
[4] Scott,A. Refining Catalysts. Chemical Week, 165 (12), 27-29, Mar. 26 (2003).

[5] Marcilly,C. Oil\& Gas Science Technology-Rev. IFP, 56(5), 494-514, (2001).

[6] Furiamsk, E and.Massoth, F.E .Catal.Today.17 (19993).

[7] Hughes, R.Deactivation of Catalysts.Academic Press. Newyork.(19984).

[8] Worldwide Catalyst Report: Refining catalyst demand. Oil \& Gas J, October, 9, 84-66, (2000).

[9] Mena,M., Antony, S.Applied Catalysis B:Environmental , 71, 199-206 (2007).

[10] Mena,M., Antony, S and Ezra,K.J of Environmental Managament ,86,665-681, (2008).

[11] Rapaport,D. Hydrocarbon process ,79,11. (2000).

[12] United Stated Environmental Protection Agency (USEPA). Hazardous waste management system fedral register, 86, (202), 59935 (2003).

[13] Lassner, J.A., Lasher, L.B., Koppel, R,L and Hamillon, I..N. Chem. Eng. Progs. Augest, 95 (1994).

[14] Kulions, T. US Pat. 4992071 (1990).

[15] Kawaskami. Jpn, Pat. 44755 (1977).

[16] Anonymous. Oil .Gas J, 56, 12 October (1992).

[17] Chang,T.J. Oil\&Gas ,79-84 October (1998).

[18] Trimm, D.L. The regeneration or disposal of deactivated heterogeneous catalyst Applied Catalysis A, 212, 153-160, (2001).

[19] Huan-qun, LIU. Recovering of spent catalyst in the foreign country. J. Chinese Resource Comprehensive Utilization, (in Chinese) (12) , 35-37, (2000)

[20] Marafi, M., Stanislaus, A . Studies on rejuvenation of spent hydroprocessing catalysts by leaching of metal foulants. Journal of Molecular Catalysis A: Chemical 202, 117$125,(2003 b)$.

[21] Berrebi, G., Dufresne, P., Jacquier, Y. Recycling spent hydro-processing catalysts: Eurecat Technology. Resources, Conservation and Recycling, 10, 1-9 (1994).

[22] Case, A., Garretson, G., Wiewiorowski, E. Ten years of catalyst recycling: a step to the future. In: Presented at the Third International Symposium on Recycling of Metals. Point Clear. Alabama, USA November 12-15,(1995).

[23] Lianos, Z.R., Deering, W.G.,. GCMC's integrated process for recovery of metals from spent catalysts. In: Presented at the Air and Waste Management Association's 90th. Annual Meeting Toronto. Canada, June 8-13,(1997).

[24] Kar, B.B., Datta, P., Misra, V.N. Spent catalyst: secondary source of molybdenum recovery. Hydrometallurgy ,72, 87-92,(2004)

[25] Marafi, M., Furimsky, E. Selection of organic agents for reclamation of metals from spent hydroprocessing catalysts. Erdol Erdgas Kohle ,121, 93-96,(2005).

[26] Chen, Y., Feng, Q., Shao, Y., Zhang, G., Ou, L., Lu, Y. Research $\backslash$ on the recycling of valuable metals in spent Al2O3-based catalyst. Material Engineering ,19, 94-97,( 2006).

[27] Chang, T. ABI/Inform Global. Oil and Gas J October 19,6,43,(1998).

[28] Menoufy,M.F and Ahmed,H.H. Tretment and reuse of spent hydrotreating catalyst.Energy Source. PartA. 30:000-000,(2008)

[29] Fang,Q., Chen,Y., Shao,Y.H., Zhang, G.F., Ou, L.M .,Lu,Y.P. J Csut,13,(2),(2006)

[30] E. Z. Hegazy., M.Sc. Thesis, Tanta University, Tanta (2003) 
[31] M. F. Menoufy, H. S. Ahmed, in Proc. of the OAPEC Seminar on Energy Conservation and Environmental Protection in Petroleum Industries, Cairo (2004).

[32] M. F. Menoufy, H. S. Ahmed, .Energy Sources, Part A, 30:1213-1222, (2008)

[33] H S. Ahmed, M.F. Menoufy., Chem. Eng Technol., 32, No. 6, 873-880, (2009) 


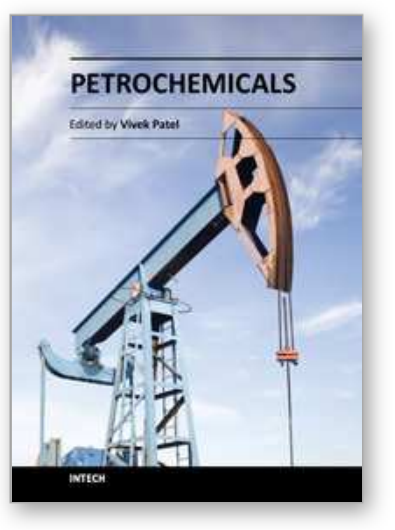

\author{
Petrochemicals \\ Edited by Dr Vivek Patel
}

ISBN 978-953-51-0411-7

Hard cover, 318 pages

Publisher InTech

Published online 28, March, 2012

Published in print edition March, 2012

The petrochemical industry is an important constituent in our pursuit of economic growth, employment generation and basic needs. It is a huge field that encompasses many commercial chemicals and polymers. This book is designed to help the reader, particularly students and researchers of petroleum science and engineering, understand the mechanics and techniques. The selection of topics addressed and the examples, tables and graphs used to illustrate them are governed, to a large extent, by the fact that this book is aimed primarily at the petroleum science and engineering technologist. This book is must-read material for students, engineers, and researchers working in the petrochemical and petroleum area. It gives a valuable and costeffective insight into the relevant mechanisms and chemical reactions. The book aims to be concise, selfexplanatory and informative.

\title{
How to reference
}

In order to correctly reference this scholarly work, feel free to copy and paste the following:

Hoda S. Ahmed and Mohammed F. Menoufy (2012). New Trends in Hydroprocessing Spent Catalysts Utilization, Petrochemicals, Dr Vivek Patel (Ed.), ISBN: 978-953-51-0411-7, InTech, Available from: http://www.intechopen.com/books/petrochemicals/reuse-and-treatment-of-hydrotreating-spent-catalyst

\section{INTECH}

open science | open minds

\section{InTech Europe}

University Campus STeP Ri Slavka Krautzeka 83/A 51000 Rijeka, Croatia Phone: +385 (51) 770447 Fax: +385 (51) 686166 www.intechopen.com

\author{
InTech China \\ Unit 405, Office Block, Hotel Equatorial Shanghai \\ No.65, Yan An Road (West), Shanghai, 200040, China \\ 中国上海市延安西路65号上海国际贵都大饭店办公楼405单元 \\ Phone: +86-21-62489820 \\ Fax: +86-21-62489821
}


(C) 2012 The Author(s). Licensee IntechOpen. This is an open access article distributed under the terms of the Creative Commons Attribution 3.0 License, which permits unrestricted use, distribution, and reproduction in any medium, provided the original work is properly cited. 